\title{
The Structure of Urethral Epithelium in Merinos Lambs
}

\author{
Vasile RUS $^{1 *}$, Bianca MATOSZ ${ }^{1}$, Flavia RUXANDA ${ }^{1}$ \\ ${ }^{1}$ Faculty of Veterinary Medicine, USAMV Cluj-Napoca, Romania \\ *corresponding author: vasile.rus@usamvcluj.ro
}

Bulletin UASVM Veterinary Medicine 75(1)/2018

Print ISSN 1843-5270; Electronic ISSN 1843-5378

doi:10.15835/buasvmcn-vm:000917

\begin{abstract}
The aim of this study was to investigate by histological techniques the structure of urethral epithelium in lambs. In this study, we harvested several fragments (prostatic, membranous and cavernous) from urethra from 5 merino's lambs of 3 months old. The first anatomical segment, the prostatic urethra, is lined by a urinary epithelium. The intermediary layer of this epithelium is formed of 5-6 rows of oval cells. The second segment of urethra has the same type of epithelium but the intermediary layer is formed of 6-7 rows of oval cells. In the last anatomical segment, the penile urethra, the epithelium is the same, but the intermediary layer has 3-4 rows of oval cells. In lambs, the urethra is lined by urinary epithelium. The urethral epithelium does not have the same thickness in all segments. The thinner epithelium it is in the cavernous urethra, the ticker is the membranous urethra.
\end{abstract}

Keywords: epithelium, lamb, urethra.

\section{Introduction}

The urethra is longer in males and has the following segments: prostatic urethra, membranous urethra and cavernous urethra (Gal and Miclăuș, 2013). Generally in adult's males, the first segment is represented by urothelial type epithelium, the second segment has stratified columnar epithelium and in the last segment, the epithelium becomes non-keratinized squamous stratified (Lesson and Lesson, 1971). In literature is mentioned the structure of the epithelium in adult animals and we did not find any studies made on young animals. Some authors affirm that the urothelium and the urethral epithelium have same embryologic origin, but the genes expressed by the cells present in the urothelium are not the same with those expressed by the cells present in the urethral epithelium (de Graaf et al., 2017). In humans, for the urethral reconstruction is used the urothelium or the oral mucosal cells, but the urethral grafts are not fully successful (de Kemp et al., 2015). It is very important to know the structure of urethral epithelium in young animals in reconstruction of the urethral wall after different pathological situations, such as urethral stricture or congenital disorders.

The aim of this study was to investigate by histological techniques the structure of urethral epithelium in lambs.

\section{Materials and methods}

In this study we used 5 merinos lambs of 3 months old. We harvested fragments from urethra, from 3 different zones: prostatic, membranous and cavernous. The samples were fixated in Stieve solution, dehydrated in ethylic alcohol, clarified in n-butanol and embedded in paraffin. The samples were sectioned at $5 \mu \mathrm{m}$ thickness and stained using Goldner's trichrome method.

\section{Results and discussions}

The first anatomical segment, the prostatic urethra, is lined by a urinary epithelium. The intermediary layer of this epithelium is formed by 5-6 rows of oval cells (fig. 1). The second segment of urethra has the same type of epithelium but the 


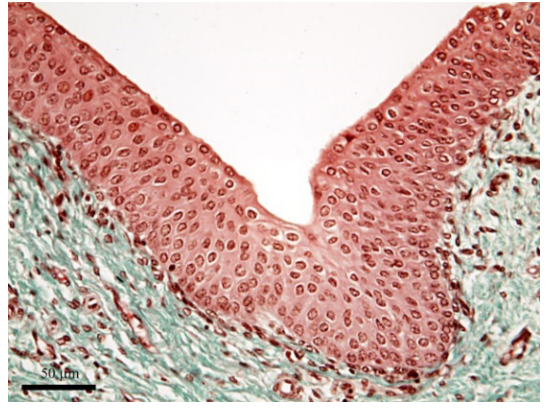

Figure 1. Prostatic urethra epithelium, Goldner's trichrome stain

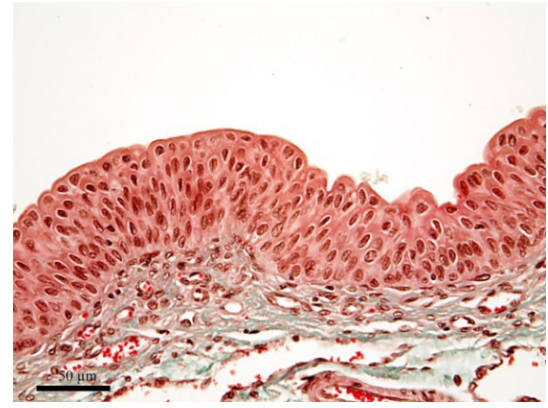

Figure 2. Membranous urethra epithelium, Goldner's trichrome stain

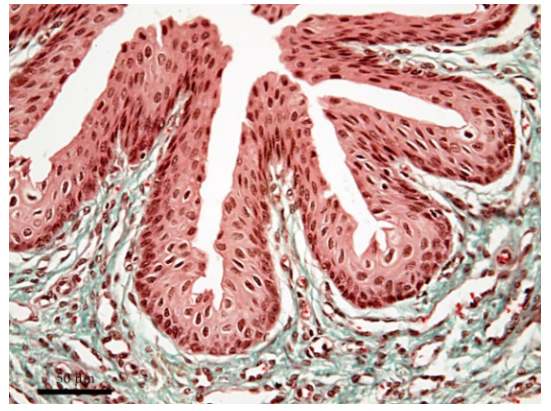

Figure 3. Cavernous urethra epithelium, Goldner's trichrome stain intermediary layer is formed by 6-7 rows of oval cells (fig 2). In the last anatomical segment, the penile urethra, the epithelium is also the same, but the intermediary layer has 3-4 rows of oval cells (fig.3). Our results show differences between the structures of the urethral epithelium described by others authors (Lesson and Lesson, 1971; Gal and Miclăuș, 2013).This differences of the epithelium structure which lined the urethra is probably typical for young animals. As some authors assert, the presence of the urothelium in young animals urethra (3 months old) may be found because the urethral epithelium has the same embryological origin as the bladder (de Graaf et al., 2017), and probably with the sexual development, this epithelium is transformed.

\section{Conclusions}

In lambs, the urethra is lined by urinary epithelium. The urethral epithelium does not have the same thickness in all segments. The thinner the epithelium in the cavernous urethra, the ticker the membranous urethra is.

Acknowledgments. This research did not receive any specific grant from funding agencies in the public, commercial, or not-for-profit sectors.

\section{References}

1. de Graaf P, van der Linde EM, Rosier PFWM, Izeta A, Sievert KD, Bosch JLHR, de Kort LMO (2017). Systematic review to compare urothelium differentiation with urethral epithelium differentiation in fetal development, as a basis for tissue engineering of the male urethra. Tissue Eng Part B Rev, 23: 257-267.

2. de Kemp V, de Graaf P, Fledderus JO, Ruud Bosch JLH, de Kort LMO (2015). Tissue engineering for human urethral reconstruction: systematic review of recent literature. PLoS One, 10: e0118653.

3. Gal AF, Miclăuș V (2013). Histology. Cluj-Napoca: Risoprint Publishing House.

4. Leeson TS, Leeson CR (1971). Histologie. Paris: Masson et Cie. 